\title{
In silico approach to prevent soft rot in vegetable crops
}

\author{
N.C. Nisha ${ }^{1}$, S. Sreekumar ${ }^{2}$, C.K. Biju ${ }^{3}$, and P. N. Krishnan ${ }^{4}$ \\ 1,2,3,4 Biotechnology and Bioinformatics Division Saraswathy Thangavelu Centre, Jawaharlal Nehru Tropical \\ Botanic Garden and Research Institute Puthenthope, Thiruvananthapuram $695586 .{ }^{2}$ Corresponding author
}

\begin{abstract}
Soft rot is a serious disease among vegetable crops that leads to high rate of economic loss to farmers. The disease is mainly caused by gram negative bacteria belonging to Pectobacterium species. The main symptom is necrosis due to degradation of cell wall by the activity of certain exo-enzymes (Plant Cell Wall Degrading Enzymes) which is produced by the bacteria in accordance with quorum sensing and signal transduction. The present study focused to control the synthesis of autoinducer called Acyl homoserine lactone, which modulates quorum sensing through the inhibition of Methionine S-adenosyl transferase (S-adenosyl methionine synthase) and Acyl homoserine lactone synthase enzymes. The inhibitory activities of Cycloleucine on Methionine S-adenosyl transferase and S-adenosyl methionine analogs on Acyl homoserine lactone synthase were studied by docking method using AutoDock 4.2. The results obtained indicate that the organic molecules used for the inhibition of targeted enzymes may be the best choice for the control of soft rot in vegetable crops.

Keywords: Soft rot, Quorum sensing, Cycloleucine, Pectobacterium carotovora, Docking.
\end{abstract}

\section{Introduction}

Soft rot is a bacterial disease in major vegetable and ornamental crops that leads to high economic loss to the farmers. The disease is mainly caused by Pectobacterium carotovorum which is a gram negative necrotrophic pathogenic bacterium belongs to the family Enterobacteriaceae which have the capability of killing plant tissues rapidly, though their aggressiveness varies. It is a rod shaped, peritrichous and facultatively anaerobic enterobacterium causes soft rot in most of the vegetables especially in cucurbits, carrot and blackleg infection in potato. The bacteria are unable to penetrate into plant cell wall until a wound is formed by infestation of fruit flies or the activity of other vectors. After intrusion, the bacteria secrete virulence factors or Plant Cell Wall Degrading Enzymes (PCWDEs) viz., cellulases, proteases and pectic enzymes (pectate lyases, pectin methylesterases, pectin lyases, polygalacturonases, proteases, lipases, and xylanases). Production of PCWDEs and the pathogenecity are depending upon quorum sensing of signal transduction mechanism.

Quorum sensing is an intra generic communication mechanism, used by bacteria to sense and respond towards various signals[1]. Quorum sensing is required for coordination community behaviour of bacteria while it is not necessary for their survival. The expression of a set of specialised genes for pathogenecity are mediated by very important quorum sensing intercellular signaling molecules or autoinducers called Acyl homoserine lactones (AHLs)[2,3]. To date, about six different quorum sensing pathways have been identified; hence different bacteria use different pathways and autoinducers for their community behaviours. The gram negative bacteria use AHLs and gram positive bacteria use autoinducing peptides (AIPs) as signaling molecules $[4,5,6]$. The basic structure of AHLs is a fatty acyl chain bound with an amide bond to homoserine lactones and may vary according to biochemical and physiological functions. However, in gram negative bacteria different regulatory proteins (Lux-R like family) are involved in quorum sensing. The quantity of signal molecule or autoinducer produced by a bacterium (autoinduction) is very less and hence it needs a particular threshold quorum to enhance pathogenecity[7]. Increase in bacterial population density leads to corresponding increase in AHL concentration. AHLs at a particular threshold concentration activate a positive transcription factor (Lux Rtype response regulator) and modulate the expression of quorum sensing-regulated genes (PCWDEs producing genes). AHLs are produced from the substrate S-adenosyl-L-methionine (SAM) and an acylated acyl carrier protein (acyl-ACP) in the presence of an enzyme AHL synthase. SAM is synthesized from methionine and adenosine triphosphate (acyl-ACP) which is catalyzed by Methionine adenosyl transferase (MAT). Presumably, molecules which can negatively regulate the synthesis of AHLs through the inhibitors of AHL synthase and MAT might be an excellent tool for eradication of pathogenecity caused by gram negative bacteria. These molecules can correlate the community level inhibition of bacterial pathogenecity and it cannot cause total destruction of the entire bacterial flora; because different bacteria use different pathways and signal molecules. According to Hentzer and Givskov (2003), the SAM analogues viz., S-adenosyl cystein, S-adenosyl homocystein and sinefungine have inhibitory effect on AHL synthase in Psuedomonas aeruginosa[8]. Hanzeller and Greenberg (1996) reported that 'cycloleucine' and MAT can negatively regulate the production of SAM in Vibrio fischery[9]. In the present study we analysed the inhibitory activity of SAM analogs on AHL synthase and cycloleucine on MAT of $P$. carotovorum by docking method. 


\section{Preparation of macromolecules}

\section{Materials And Methods}

The 3D structures of MAT and AHL synthase of P. carotovorum subsp. carotovora were not available in RCSB Protein Data Bank. The structures of these molecules were modelled with SWISSMODEL[10,11,12]. The primary sequences of AHL (sp ID: Q6D081synthase) and MAT (sp ID: P33882) were retrieved from Swissprot. The templates were selected by submitting the sequences on online Basic Local Alignment Search Tool for protein (BLASTp) on NCBI web site. Based on E-value or similarity score of the alignment and 3D structure availability Acyl homoserine lactone synthase of Pantoea stewartii subsp. stewartii PDB ID-1K4J Chain A, E-value 2e-176[13] and Methionine adenosyl transferase of Escherichia coli, PDB ID-1FUG Chain A, E-value 8e-27[14] were selected as templates. The sequences of both templates and target sequences were submitted on SWISSMODEL workspace as ClustalW (Fig. 1a \& b) alignment input format. The 3D structure and Ramachandran plot of modelled structures (Fig. 2) were analysed by Deep View/Swiss-Pdb Viewer 4.0.1. The energy minimization of the modelled structures of AHL synthase and MAT were done using GROMOS 96 (implemented in Deep View/Swiss-Pdb Viewer) and confirmed their structural stability.

\section{Preparation of ligands}

The Canonical SMILES of Cycloleucine (CID-2901), SAM, its analogues such as S-adenosyl cysteine (CID-3573837), S-adenosyl methionine (CID-34755) and S-adenosyl homocysteine (CID-439155) were obtained from PubChem and 3D structures were generated using CORINA, the online 3D generation software. The docking was done using an automated and widely used molecular docking open access tool, Autodock 4.2. The tool use Monte Carlo simulated annealing and Lamarckian Genetic algorithm for the generation of possible orientations of ligand. The grid spacing of 0.375 with $40 \times 40 \times 40$ points for each enzyme was defined. The grid was centred on the active site and XYZ-coordinates of AHL synthase and MAT were 18.881, -3.209, 15.721 and $26.419,17.906,58.262$ respectively. For docking, all the parameters were kept as default including population number. AHL synthase was docked with SAM (original substrate) and its analogues viz., S-(5'Adenosyl)-L-cysteine, S-adenosyl homocysteine and Sinefungin and Methionine adenosyl transferase were docked with Cycloleucine. The ligand bound complexes were analysed for its binding affinity and possible orientations were ranked according to their lowest binding energy through cluster analysis. The top ranked orientations with maximum size and inhibition constant were considered for further studies.

\section{Results And Discussion}

The Ramachandran plot analysis of the modelled structures indicated that most of the amino acids present in both the enzymes were present at the allowed regions only (Fig. 1 a \& b). Energy minimisations for stability confirmation of the modelled structures such as AHL synthase and MAT were done with GROMOS96. The results showed that total internal energy of AHL synthase and MAT was $-6195.537 \mathrm{KJ} / \mathrm{mol}$ and -3234.737 $\mathrm{KJ} / \mathrm{mol}$ respectively, which ensured the stability of the enzyme structures.

The docked results of AHL synthase was analysed with its original substrate, SAM (TABLE 1). The software uses a semiemperical free energy force field which is based on a comprehensive thermodynamic model to predict the possible conformations based on free energies of binding of small molecules to macromolecular targets[15]. These conformations were ranked according to free energy of binding which is the sum of all the force field parameters such as final intermolecular energy, van der waals interaction, hydrogen bond, desolvation energy, electrostatic energy and torsional free energy.

\section{TABLE}

Table 1. Docked results between AHL synthase and MAT with selected inhibitors.

\begin{tabular}{|c|c|c|c|c|c|c|c|}
\hline $\begin{array}{l}\text { Sl. } \\
\text { No. }\end{array}$ & Inhibitor & Enzyme & $\begin{array}{l}\mathrm{Ki} \text { in } \\
\mu \mathrm{M}\end{array}$ & $\begin{array}{l}\text { Total Free } \\
\text { Energy of } \\
\text { binding } \\
\text { Kcal/Mol }\end{array}$ & Hydrogen bond & Bond type & $\begin{array}{l}\text { Bond } \\
\text { length }\end{array}$ \\
\hline \multirow{2}{*}{1} & \multirow{2}{*}{$\begin{array}{l}\text { S-adenosyl } \\
\text { methionine * }\end{array}$} & \multirow{2}{*}{$\begin{array}{l}\text { AHL } \\
\text { synthase }\end{array}$} & \multirow{2}{*}{133.85} & \multirow{2}{*}{-5.28} & UNK1:H49 1 & $\mathrm{O}-\mathrm{H} \ldots \mathrm{O}$ & 2.065 \\
\hline & & & & & ARG41: HN 1 & $\mathrm{~N}-\mathrm{H} \ldots \mathrm{O}$ & 1.849 \\
\hline \multirow{2}{*}{2} & \multirow{2}{*}{$\begin{array}{l}\text { S-adenosyl } \\
\text { cysteine }\end{array}$} & \multirow{2}{*}{$\begin{array}{l}\text { AHL } \\
\text { synthase }\end{array}$} & \multirow{2}{*}{4.05} & \multirow{2}{*}{-3.26} & UNK1:H40 1 & $\mathrm{~N}-\mathrm{H} \ldots \mathrm{O}$ & 2.036 \\
\hline & & & & & ARG41:HN 1 & $\mathrm{~N}-\mathrm{H} \ldots \mathrm{O}$ & 1.832 \\
\hline \multirow{2}{*}{3} & \multirow{2}{*}{$\begin{array}{l}\text { S-adenosyl } \\
\text { homocysteine }\end{array}$} & \multirow{2}{*}{$\begin{array}{l}\text { AHL } \\
\text { synthase }\end{array}$} & \multirow{2}{*}{139.58} & \multirow{2}{*}{-5.26} & UNKO:H 1 & $\mathrm{O}-\mathrm{H} \ldots \mathrm{O}$ & 2.148 \\
\hline & & & & & UNKO:H 1 & $\mathrm{O}-\mathrm{H} \ldots \mathrm{O}$ & 1.826 \\
\hline \multirow{3}{*}{4} & \multirow[t]{3}{*}{ Sinefungin } & \multirow{2}{*}{$\begin{array}{l}\text { AHL } \\
\text { synthase }\end{array}$} & \multirow{3}{*}{653.96} & \multirow{3}{*}{-4.34} & UNK1:H45 1 & $\mathrm{~N}-\mathrm{H} \ldots \mathrm{O}$ & 2.054 \\
\hline & & & & & THR67:H49 1 & $\mathrm{O}-\mathrm{H} \ldots \mathrm{O}$ & 1.737 \\
\hline & & \multirow[b]{2}{*}{ MAT } & & & SER39: HG 1 & $\mathrm{O}-\mathrm{H} \ldots \mathrm{O}$ & 1.735 \\
\hline 5 & Cycloleucine & & 144.46 & -5.24 & ARG257: HE 1 & $\mathrm{~N}-\mathrm{H} \ldots \mathrm{O}$ & 1.689 \\
\hline
\end{tabular}


The molecular interaction of Cycloleucine and MAT showed two strong hydrogen bonds (N-H...O) with ARG257 (Fig. 4 a), they were ARG257:HE1 and ARG257: HH21 1 with bond length of 1.689 and $1.647 \mathrm{~A}^{0}$ respectively. Similarly, S-adenosyl cysteine showed two strong hydrogen bonds with (O....H-N) ARG41:HN1 and UNK1:H401 (N-H.... a) and the bond length was $1.832 \mathrm{~A}^{0}$ and $2.036 \mathrm{~A}^{0}$ respectively. S-adenosyl homocysteine showed two strong hydrogen bonds (O-H.... ) with UNK0:H1 and UNK0:H1 of AHL synthase; the exact binding amino acid could not be distinguished. But the bond formed can be seen in between ILE82 and VAL83 and the bond length was $1.826 \mathrm{~A}^{0}$ and $2.148 \mathrm{~A}^{0}$ respectively. The molecular interaction between AHL synthase and Sinefungin showed three Hydrogen bonds with SER39:HG1 (O...H-O), THR67:H49 1 (O-H....O) and SER7:H45 1 (N-H....O) and the bonds length were $1.735 \mathrm{~A}^{0}, 1.737 \mathrm{~A}^{0}$ and $2.054 \mathrm{~A}^{0}$ (Fig. 2 b, c \& d).

The results revealed that Cycloleucine possess most inhibitory activity on MAT and Sinefungin and Sadenosyl homocysteine on AHL synthase. These inhibitors can repress the SAM and AHL production, in turn quorum sensing and pathogenecity. Hence supply of any of these molecules at the time of fruit fly infestation may be an effective method to eradicate soft rot disease. It can be applied in the form of spray during fruit setting period. Generally, antibiotics are applied as prophylactic sprays on plant surfaces to inhibit pathogen growth before infection, after infection antibiotic sprays do not control disease. However, pragmatic application method is to be elucidated through field experiments. Use of quorum quenching molecules could not induce rapid mutation and destruction of the entire bacterial flora. Antibiotics are used on fruit trees to check and eradicate microbial infection. No human health effects have been documented since inception of use of antimicrobials in plants in the 1950s[16].

\section{Figures}

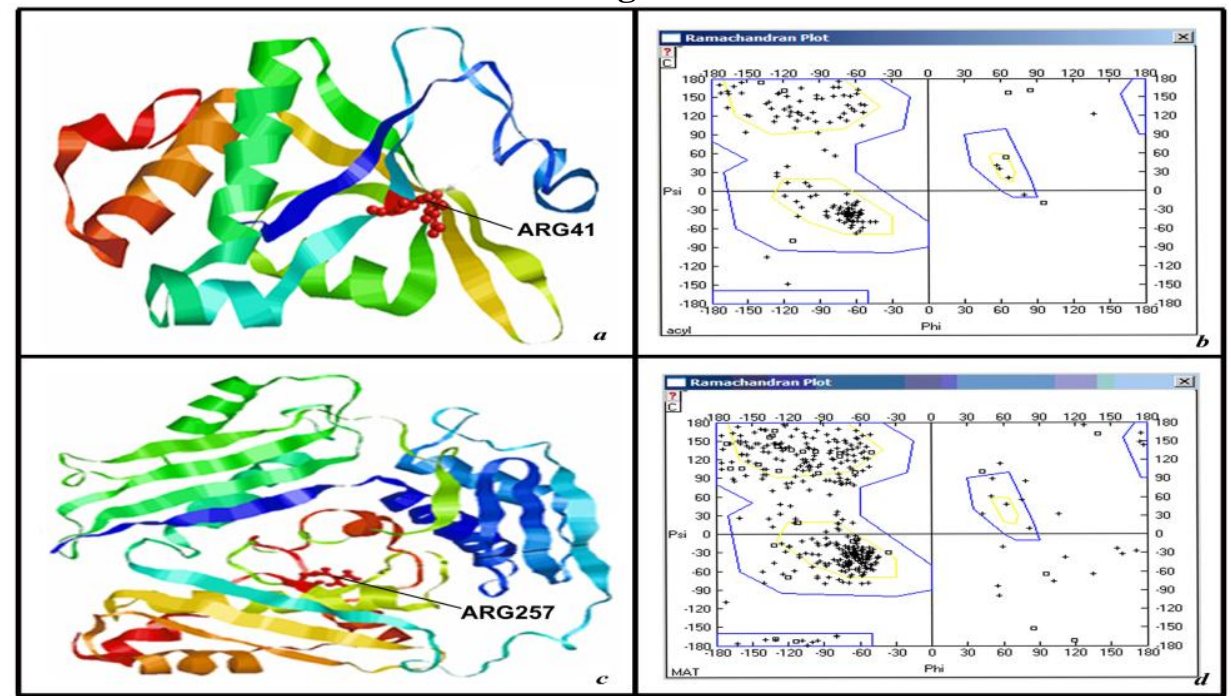

Fig. 1: a) MAT modelled structure in RasMol. b) Ramachandran plot of MAT. c) AHL synthase modelled structure in RasMol. d) Ramachandran plot of AHL synthase.

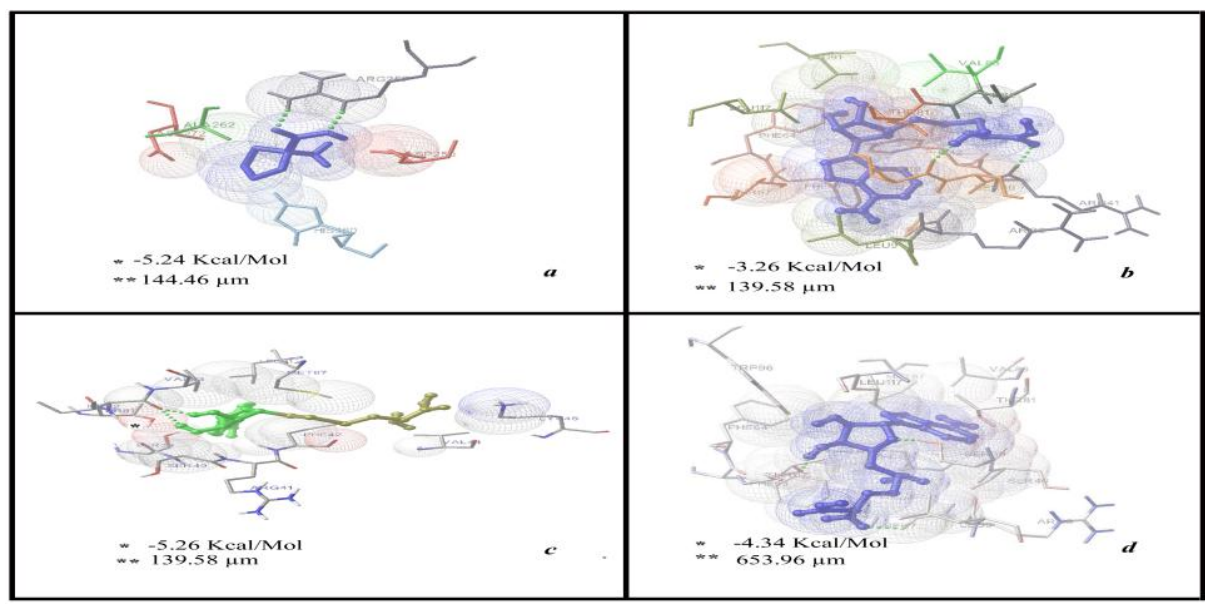

Fig. 2: Molecular interaction between a) MAT and Cycloleucine. b) AHL synthase and S-adenosyl cysteine. c) AHL synthase and S-adenosyl homocystein. d) AHL synthase and Sinefungin. *Free energy of binding, **Inhibition constant 


\section{Conclusion}

The overall results give an insight to develop quorum quenching method to eradicate soft rot disease. Further investigation is required at field level for practical application and standardization of effective dose.

\section{Acknowledgements}

We thank the Director, JNTBGRI, Dr. T. Madhan Mohan, Adviser, BITSNET, DBT, Department of Science and Technology, Govt. of India, New Delhi and Smt. Seeja G, Department of Plant Breeding and Genetics, College of Agriculture, Thiruvananthapuram for their supports and encouragements.

\section{References}

[1] N. A. Whitehead, A. M. L. Barnard, H. Slater, N. J. L. Simpson, and G. P. C. Salmond, Quorum sensing in Gram-negative bacteria. FEMS Microbiology Reviews, 25, 2001, 365-404.

[2] S. Jones, B. Yu, N. J. Bainton, M. Birdsall, B. W. Bycroft, S. R. Chhabra, A. J. R. Cox, P. Golby, P. J. Reeves, S. Stephens, M. K. Winson, G. P. C. Salmond, G. S. A. Stewart, P. Williams, The lux autoinducer regulates the production of exoenzyme virulence determinants in Erwinia carotovora and Pseudomonas aeruginosa. EMBO Journal, 12(6), 1993, 2477-2482.

[3] M. Pirhonen, D. Flego, Heikinheimo, E. T. A. Palva, Small diffusible signal molecule is responsible for the global control of virulence and exoenzyme production in the plant pathogen Erwinia carotovora. EMBO Journal, 12 (6), 1993, $2467-2476$.

[4] C. M. Waters, B. L. Bassler, Quorum sensing: Cell-to-cell communication in bacteria. Annual Review of Cell and Developmental Biology, 21, 2005, 319-346.

[5] M. B. Miller, B. L. Bassler, Quorum sensing in bacteria. Annual Review of Microbiology, 55, 2001, $165-199$.

[6] M. Sturme, M. Kleerebezem, J. Nakayama, A. Akkermans, E. Vaughan, W. de Vos, Cell to cell communication by autoinducing peptides in gram-positive bacteria. Antonie van Leeuwenhoek, 81, 2002, 233-243.

[7] A. M. L. Barnard, S. D. Bowden, T. Burr, S. J. Coulthurst, R. E. Monson, G. P. C. Salmond, Quorum sensing, virulence and secondary metabolite production in plant soft-rotting bacteria. Philosophical Transactions of the Royal Society, B 362, 2007, 11651183 .

[8] M. Hentzer, M. Givskov, Pharmacological inhibition of quorum sensing for the treatment of chronic bacterial infections. The Journal of Clinical Investigation, 112(9), 2003, 1300-1307.

[9] B. L. Hanzelka, E. P. Greenberg, Quorum sensing in Vibrio fischeri: Evidence that S-Adenosylmethionine is the amino acid substrate for autoinducer synthesis. Journal of Bacteriology, 178(17), 1996, 5291-5294.

[10] K. Arnold, L. Bordoli, J. Kopp, T. Schwede, The SWISS-MODEL Workspace: A web-based environment for protein structure homology modelling. Bioinformatics, 22, 2006, 195-201.

[11] T. Schwede, J. Kopp, N. Guex, M. C. Peitsch, SWISS-MODEL: An automated protein homology-modelling server. Nucleic Acids Research, 31(13), 2003, 3381-3385.

[12] N. Guex, M. C. Peitsch, SWISS-MODEL and the Swiss-PdbViewer: An environment for comparative protein modelling. Electrophoresis, 18, 1997, 2714-2723.

[13] W. T. Watson, T. D. Minogue, D. L. Val, S. B. von Bodman, M. E. Churchill, Structural basis and specificity of acyl-homoserine lactone signal production in bacterial quorum sensing. Molecular Cell, 9(3), 2002, 685-94.

[14] Z. Fu, Y. Hu, G. D. Markham, F. Takusagawa, Flexible loop in the structure of S-adenosyl methionine synthetase crystallized in the tetragonal modification. Journal of Biomolecular Structure \& Dynamics, 13(5), 1996, 727-39.

[15] G. M. Morris, R. Huey, W. Lindstrom, M. F. Sanner, R. K. Belew, D. S. Goodsell, A. J. Olson, AutoDock4 and autoDock tools 4:Automated docking with selective receptor flexibility. Journal of Computational Chemistry, 30(16), $2009,2785-91$.

[16] A. K. Vidaver, Use of antimicrobials in plant agriculture. Clinical Infectious Diseases, 34(3), 2002, S107-10. 